\title{
Correction to: An efficient dual prediction-based reversible data hiding and reduced code method for AMBTC
}

\author{
Chin-Chen Chang ${ }^{1} \cdot \mathrm{Xu} \mathrm{Wang}^{1} \cdot{\text { Chia-Chen } \operatorname{Lin}^{2}}^{10}$
}

Published online: 8 October 2021

(c) Springer Science+Business Media, LLC, part of Springer Nature 2021

\section{Correction to: Multimedia Tools and Applications (2021) https://doi.org/10.1007/s11042-021-11048-y}

In the original publication of this article, the corresponding author was incorrect. The original article has been corrected.

Publisher's note Springer Nature remains neutral with regard to jurisdictional claims in published maps and institutional affiliations.

The original article can be found online at https://doi.org/10.1007/s11042-021-11048-y.

Chia-Chen Lin

ally.cclin@ncut.edu.tw

Chin-Chen Chang

alan3c@gmail.com

Xu Wang

wx1990555@gmail.com

1 Department of Information Engineering and Computer Science, Feng Chia University, 100

Wenhwa Road, Seatwen, Taichung 40724, Taiwan

2 Department of Computer Science and Information Engineering, National of Chin-Yi University of Technology, Taichung 411030, Taiwan 